\title{
IDENTIDADES SUBALTERNAS: EDAD, CLASE, GÉNERO Y CONSUMOS CULTURALES
}

MALVINA SILBA*

\begin{abstract}
RESUMEN
Este trabajo propone discutir una aproximación a la problemática de la identidad en mujeres y varones jóvenes de sectores populares en torno a tres categorías: edad, clase y género. Las mismas permiten señalar ejes a partir de los cuales estos sujetos experimentan la condición de subalternidad. El abordaje etnográfico, eje central de esta reflexión, permitirá contrastar los sentidos nativos de los sujetos que son objeto de esta reflexión, con ciertas imágenes culturales que circulan hoy sobre los jóvenes y que encuentran en éstos una suerte de condensación de «males sociales» que estarían afectando y poniendo en peligro el «normal» funcionamiento de las sociedades. Conjuntamente, y frente a la pregunta ¿puede hablar el sujeto subalterno?, el objetivo del trabajo será indagar en qué medida los intelectuales estamos dispuestos a escuchar las diversas formas de comunicación de los sujetos en cuestión.
\end{abstract}

PALABRAS CLAVE: JUVENTUDES, EXPERIENCIAS SUBALTERNAS, PRÁCTICAS COTIDIANAS

* Docente de la Carrera de Comunicación Social, Universidad de Buenos Aires (UBA). Licenciada en sociología (2005) y doctora en ciencias sociales (2011). Becaria posdoctoral del Consejo Nacional de Investigaciones Científicas y Técnicas (CONICET).

Correo electrónico: malvinasilba@yahoo.com.ar. 


\title{
IDENTIDADES SUBALTERNAS: IDADE, CLASSE, GÊNERO \\ E CONSUMOS CULTURAIS
}

\begin{abstract}
Resumo
Este trabalho propõe discutir uma aproximação à problemática da identidade em mulheres e homens jovens de setores populares em torno de três categorias: idade, classe e gênero. Estas categorias permitem assinalar eixos a partir dos quais estes sujeitos experimentam a condição de subalternidade. A abordagem etnográfica, eixo central desta reflexão, permitirá contrastar os sentidos nativos dos sujeitos, que são objeto desta reflexão, com certas imagens culturais que circulam hoje sobre os jovens e que encontram nestes uma forma de condensação dos «males sociais» que estariam afetando e colocando em perigo o funcionamento «normal» das sociedades. Adicionalmente, através da pergunta: «o sujeito subalterno pode falar?», o objetivo do trabalho será indagar em que medida os intelectuais estão dispostos a escutar as diversas formas de comunicação dos sujeitos em questão.
\end{abstract}

\section{PALAVRAS CHAVE: JUVENTUDES, EXPERIÊNCIAS SUBALTERNAS,} PRÁTICAS COTIDIANAS

\section{SUBORDINATE IDENTITIES: AGE, CLASS, GENDER AND CULTURAL CONSUMPTION}

\begin{abstract}
This work intends to discuss an approach to the problem of identity in young men and women from popular sectors into three categories: age, class and gender, which would allow a central theme from which these subjects experience the condition of subordination. The ethnographic approach, the core of this discussion, will contrast the native sense of the subjects that are the subject of this discussion, certain cultural images that circulate today youth and finding in them a condensation of «social evils» that would be affecting and endangering the «normal» functioning of societies. Together, and against the subordinate question; can a subordinate subject have their say? The objective of this study intends to investigate the extent to which intellectuals are willing to listen to various forms of communication among the subjects in question.
\end{abstract}

KEY WORDS: YOUTH, SUBORDINATE EXPERIMENTS, EVERYDAY PRACTICES 


\section{INTRODUCCIÓN: LOS OBJETIVOS}

ESTE TRABAJO PROPONE DISCUTIR una aproximación a la problemática de la identidad en mujeres y varones jóvenes de sectores populares en torno a tres categorías: edad, clase y género. Las mismas permiten señalar ejes a partir de los cuales estos sujetos experimentan la condición de subalternidad. El interés de este tipo de propuestas se fundamenta en afirmaciones que rescata Spivak (1999) —a pesar de las críticas que realiza — del debate entre Foucault y Deleuze (1977) «los intelectuales deben intentar arribar a la separación y el conocimiento del discurso del Otro en la sociedad». Pero Spivak se pregunta cómo se puede acceder al discurso de ese «otro», y entonces afirma «¿acaso aquellos que actúan y luchan son mudos, en oposición a los que actúan y hablan?» (op. cit., 1999). Esta misma pregunta podría reformularse como el eje que atraviesa todo este trabajo de la siguiente manera: las mujeres y varones jóvenes que son objetos de este trabajo, como ya se verá, son «silenciados», «no escuchados» o «reprimidos» en múltiples aspectos de su vida cotidiana. Pero, ¿tienen por ello la obligación de permanecer callados? Como lo plantea la autora, ¿son en realidad mudos? O, será que debemos agudizar, profundizar y cuestionar nuestras herramientas para aprender a escucharlos y comprobar que en verdad no sólo hablan sino que tienen mucho para decir.

La intersección de los tres ejes antes mencionados con cierto tipo de prácticas - los consumos culturales y las distintas formas de violencia- ponen en escena la complejidad y variabilidad de la construcción identitaria contemporánea y la necesidad de tener en cuenta estos factores de manera simultánea y compleja a la hora de analizarla.

\section{EL OBJETO: LOS JÓVENES, ${ }^{1}$ EL BARRIO Y SU VIDA COTIDIANA}

La propuesta de analizar la identidad en jóvenes de sectores populares se enmarca en mi investigación doctoral, para la cual realicé trabajo de campo etnográfico durante un año en un barrio de la zona sur del Conurbano Bonaerense. El grupo al que acompañé estaba compuesto en

1 El uso del masculino genérico ‘jóvenes’, en algunos casos a lo largo del trabajo, designa tanto a las mujeres como a los varones que conforman dicho colectivo y no pretende entrar en contradicción con las preocupaciones manifestadas en relación con las problemáticas de género, sino que responde meramente a cuestiones estilísticas. 
ese momento por mujeres y varones entre los doce y veintitrés años. Los mismos residían en un barrio de clases populares, llamado «Los Sauces» y ubicado a treinta cuadras de la estación de trenes de Burzaco, Partido de Almirante Brown. ${ }^{2}$ Hasta allí sólo llegaban dos líneas de colectivos que funcionaban con irregularidad, sobre todo los fines de semana. Las primeras imágenes mostraban un barrio de casas bajas, con negocios de rubros variados sobre la calle principal y un asfalto deteriorado con pozos que adornaban regularmente cada una de las esquinas.

Los lugares habituales de encuentro del grupo y donde pasaban su tiempo era la plaza — que ocupaba una manzana y tenía algunos juegos, mesas y una precaria canchita de fútbol—; y la esquina de la casa de uno de los chicos que contaba con una vereda amplia para sentarse. Sólo algunas de las calles de ese circuito estaban asfaltadas, el resto aún era de tierra, lo que dificultaba la circulación en especial durante los días de lluvia. El barrio combinaba construcciones de material con otras más precarias de madera o chapa. Algunos de los terrenos históricamente baldíos fueron ocupados por familias que comenzaron a construir allí sus viviendas. Frente a la plaza estaba la escuela que ocupaba media manzana, cuya pintura y alambrados que la cercaban se veían visiblemente deteriorados. También se observaban varios negocios dentro de las casas, en especial quioscos y almacenes. El barrio estaba rodeado por otros de características similares, algunos de los cuales son conocidos como «villas» 0 «terrenos tomados».

¿Cómo se inscriben la problemática de la identidad en este contexto? La propuesta es relacionar los consumos culturales de estos jóvenes, centrales en la construcción identitaria de los mismos, con tres ejes que señalan una serie de alteridades que condicionan cotidianamente su vida: edad, clase y género. Por otra parte, existe un conjunto de prácticas asociadas al consumo musical —el baile, la escucha musical y las diferentes formas de violencia, física o simbólica- que ponen en escena los conflictos, los miedos, los deseos y las necesidades de este grupo. En este punto las preguntas que señala Hall (1996) en torno al debate sobre la identidad: «no tanto ¿quiénes somos? o ¿de dónde venimos?, sino ¿en qué podríamos convertirnos?» son totalmente pertinentes. Y con esto, la idea de que si bien la identidad ya no puede ser «integral, originaria y unificada»; esto es, no se puede responder sobre «quiénes somos o de dónde venimos», porque las condi-

2 Los nombres de las personas y de los lugares han sido modificados a fin de preservar su privacidad. 
ciones de posibilidades histórico-sociales y políticas que hacían viables esas preguntas han cambiado radicalmente, sí es verdad que al ser la identidad un concepto "clave» demuestra que es «una idea que no puede pensarse a la vieja usanza, pero sin la cual ciertas cuestiones clave no pueden pensarse en absoluto» (op. cit., 1996).

No interesa entonces indagar sobre identidades fijas, inamovibles o definibles en torno a un solo eje (clase, género, edad, etcétera) como preguntarse por el proceso mismo de construcción en torno a esos ejes, interceptado con la serie de prácticas mencionadas. Para el caso propuesto, las preguntas podrían ser ¿en qué tipo de sujetos se están constituyendo estos jóvenes? ¿Atravesados e interpelados por qué circunstancias, por cuáles instituciones y discursos?

Pero también obligan a la reflexión las otras preguntas de Hall: ¿cómo los han representado y cómo atañe ello al modo en cómo podrían representarse? ¿Cuáles son las imágenes culturales (Feixa, 1998) que circulan en la Argentina actual sobre los varones y mujeres jóvenes de sectores populares? ¿Cuáles son las expectativas y los prejuicios que la sociedad ha depositado en ellos? Los discursos y las representaciones sociales, reforzados muchas veces por la labor de los medios de comunicación, conforman un sentido común hegemónico que la mayoría de las veces pareciera estar depositando en los jóvenes todos los males de la sociedad, sus miedos y fracasos, sus debilidades, falencias y descontentos, no sólo por su condición etaria, sino por el agregado de la posición social: son jóvenes, y además pobres. En palabras de Jean Monod (1970): «El orden de las subculturas juveniles más 'alarmantes', hacia las cuales la sociedad se gira con sorpresa como un espejo demasiado verdadero de ella misma, no es el fruto del azar sino el producto de una óptica interna según la cual la sociedad expresa sus contradicciones e intenta suprimirlas en sectores localizados, y los ve resurgir en otros lados bajo nuevas formas».

Contribuir a desnaturalizar ese sentido común es uno de los objetivos centrales de nuestro trabajo, ya que consideramos que es una tarea tan necesaria como urgente. En esa línea, el trabajo de campo etnográfico, al permitir cambiar «el eje de la mirada», aproximándose lo más posible a la «perspectiva del actor», colabora a reconstruir la complejidad y variabilidad del mundo social en el que estos sujetos viven, trabajan, luchan y sueñan cotidianamente, sin perder de vista las relaciones de poder que atraviesan la totalidad del entramado social, e incluso la reproducción de la dominación y la desigualdad al interior de estos grupos. 


\section{IDENTIDADES: TEORÍA PARA DEBATIR, ENRIQUECER (Y ¿EXPLICAR?) LA EXPERIENCIA}

Hall (1997), a propósito de la relación entre teoría y praxis en su obra, afirma: «Siempre me intereso por seguir teorizando sobre el mundo, sobre lo concreto, pero no estoy interesado en la producción de teoría como objeto a título propio. Y por tanto, uso las teorías en forma estratégica [...] es porque considero que mi objeto es pensar en la concreción del objeto en sus muchas relaciones diversas».

Partiendo de estas afirmaciones, entonces, no debatiremos en este apartado los diferentes enfoques teóricos sobre la identidad sino que utilizaremos sólo algunos de esos enfoques a fin de analizar la experiencia de campo mencionada.

\section{a) Juventud: ¿divino tesoro o maldita transición?}

Todo grupo social, al construir sus identidades, marca una alteridad, se diferencia uno del otro. Hall (1996) afirma que las mismas «son más el producto de la marcación de la diferencia y la exclusión que signo de una unidad idéntica y naturalmente constituida: se constituyen a través de la diferencia, no al margen de ella». ¿De quiénes se diferencian los jóvenes que son objetos de este trabajo? En principio, del mundo de los adultos. Como afirma Chaves (2005), la experiencia etaria puede ser analizada como generadora de identidad, y la condición juvenil, como otra de las formas de experimentar la subalternidad. «Ser joven» estaría señalando, en un mundo regido por el «adultocentrismo» (Chaves, 2005), una carencia, una falta, y a su vez, una etapa transitoria, por la que todas las personas pasan en algún momento y a la que, en teoría, «superarían» con el paso del tiempo, la acumulación de experiencia y la constitución de un supuesto «sujeto completo»: personas adultas, responsables, trabajadoras, respetuosas de las normas, disciplinadas, etcétera. La mujer y el varón joven es concebido/a desde este paradigma como un sujeto incompleto, atravesando una especie de «etapa excepcional» dentro de su vida, que es a la vez de «crisis» y/o inestabilidad emocional», lo cual explica que muchas veces se diga de los/as jóvenes «que no saben lo que hacen» o que «ya se les va a pasar», y una etapa de «moratoria social» (Margulis y Urresti, 1998), lo que en teoría les permite no estar obligados a ingresar al sistema productivo de manera inmediata sino que pueden «dedicarse a disfrutar de la vida por un tiempo» que siempre es limitado, 
debatido y cuestionado socialmente. Pero, si bien la «crisis» es una condición inherente a cualquier joven, en tanto se la define como un atributo psicológico universal propio de la «edad y de los cambios hormonales» (Stanley Hall, 1904), la «moratoria social» no cumple —ni puede cumplir - con el requisito de la universalidad. No todos los adolescentes y jóvenes son eximidos de la obligación de ingresar al mercado laboral de manera temprana. En este punto, se hace indispensable diferenciar a estas mujeres y varones jóvenes de acuerdo a la posición que ocupan en la estructura social, para poder contextualizar sus experiencias de acuerdo a las limitaciones y ventajas con que cada grupo social cuenta. Este punto será retomado en el próximo apartado, al abordar la problemática de la clase social.

El mundo adulto estaría representando para los jóvenes por todo lo relacionado con la autoridad. En ese sentido, no sólo se opondrían a las personas adultas de manera individual, sino también a las instituciones que éstos representan, como la escuela, el trabajo, y fundamentalmente, las fuerzas de seguridad: la policía, el ejército, etcétera). Es pertinente señalar que las categorías de adultez y juventud no son definidas de manera sustancialista sino relacional. Esto significa que no hay una definición única o ahistórica de juventud y que las variadas formas de «ser joven», en contraposición a "ser adulto», van cambiando de acuerdo al momento histórico, al contexto social y político, y al estado de relaciones (más o menos complejas) entre los diferentes grupos de edad.

Plantea Chaves (2005) «El punto de partida es (debe ser) la visión del joven como ser en relación. El/la joven como actores sociales completos, inmersos en relaciones de clase, de edad, de género, étnicas, cuyo análisis corresponde ser encarado desde una triple complejidad: 1) contextual: espacial e históricamente situado; 2) relacional: conflictos y consensos; 3) heterogénea: diversidad y desigualdad». (cursivas de la autora).

Pensar la cuestión etaria como otra forma de experimentar la subalternidad ayuda a reflexionar permanentemente sobre el propio alcance de la categoría subalterno, en tanto ésta representa a los «grupos oprimidos y sin voz, el proletariado, las mujeres, los campesinos, aquellos que pertenecen a grupos tribales» (Giraldo, 2003). Si los jóvenes aquí mencionados pueden o no ubicarse en la categoría de «tribu» es un debate que excede este espacio de discusión. Pero lo que sí es posible problematizar es la cuestión de la opresión y de la voz. En un mundo regido por la legitimidad del adultocentrismo, el hecho de que los jóvenes 
constituyan un grupo oprimido -en ocasiones reprimido y a la vez silenciado en sus expectativas, deseos y elecciones presentes y futuras, da cuenta de que su subalternidad no es sólo una cuestión retórica sino que tiene una materialidad dramáticamente vigente.

Estas mujeres y varones jóvenes, entonces, encuentran en el mundo adulto (por diversos motivos) una otredad; aquella (o)presión de la que quieren diferenciarse y a la vez liberarse. Y las formas que encuentran para lograrlo son tan variadas como complejas y contradictorias. Pero si de complejidad se trata, ¿qué ocurre cuando a la cuestión etaria se cruza con la posición social? O dicho de otra manera, ¿qué sucede cuando además de jóvenes, son pobres?

\section{b) Clase social y consumos culturales}

Los/as jóvenes objeto de nuestra investigación, son habitantes de barrios pobres de la periferia urbana, al igual que la mayoría de aquellos con quienes comparten su gusto musical por la cumbia. Este compartir no implica sólo «un gusto» sino una serie de experiencias, reconocimientos y adscripciones organizadas alrededor de esa elección musical. Sin embargo, sus consumos simbólicos no son sólo repertorios que les permiten identificarse, reunirse en torno a, o sentirse interpelados por. El proceso es, como casi siempre sucede en el análisis sociocultural, mucho más intrincado. «El significado positivo de cualquier término —y con ello su identidad— sólo puede construirse a través de su relación con el otro, la relación con lo que él no es, con lo que justamente le falta» (Hall, 1996). La identificación con la cumbia, «ser y sentirse cumbieros y cumbieras», no es una afirmación positiva, que se define por la mera elección de un estilo musical. Ésta necesita y depende, nuevamente, de establecer marcaciones diferenciales o diacríticas con ese otro, en este caso, de clase.

¿Quiénes son los «otros de clase» de los cumbieros y cumbieras? Básicamente, otros jóvenes: «los chetos» y «los roqueros» se encuentran entre los más frecuentemente mencionados. La construcción discursiva de esos «otros» no tiene en cuenta «objetivamente» la posición social —en el sentido del lugar que ocupan en la estructura socioeconómica-, sino que está relacionada a sus elecciones y consumos materiales y simbólicos. La indumentaria y música pueden señalarse como las dos variables centrales analizadas; aunque es cierto que a partir de la «lectura» de determinadas elecciones estéticas se puede inferir esa posición social. «Los chetos», entonces, a modo general se 
representan como aquellos que no tienen ninguna limitación económica porque vienen de una familia de dinero que los puede mantener, o porque aun trabajando, pueden gastarse todo lo que ganan en los objetos que desean. Así, puede ser caratulado de «cheto» aquel que vive en un barrio «más lindo» o viene de una «familia de plata», tanto como un/a vecino/a del barrio que se empeña por distinguirse de los «cumbieros y cumbieras», aunque para ello deba realizar un esfuerzo económico y simbólico extraordinario.

Hasta aquí queda claro que «los chetos» son percibidos como un «otro de clase» de manera mucho más clara que «los roqueros». Estos últimos, comparten muchas veces trayectorias escolares y laborales, el barrio y los lazos familiares y/o afectivos. Podríamos decir que la diferenciación se produce por motivos relacionados a elecciones estéticas, que son también morales. Los «roqueros» enfocan sus prácticas y discursos con ciertos sentidos de transgresión y resistencia a las imposiciones del sistema. "Los roqueros» se embanderan detrás de causas que van desde la oposición a la música comercial hasta las denuncias sobre la injusticia social. Esas causas tendrían, en principio, «un contenido más profundo y comprometido con la sociedad». Plantea Garriga (2008): «Los 'roqueros’ consideran que las letras de las bandas que escuchan deben exhibir las injusticias estructurales (pobreza, marginación, desempleo) mostrando algo que el resto de los estilos musicales supuestamente ocultan. Cuando muchos estilos ponen el énfasis en la diversión y el baile, el rock, por el contrario, debe hacer hincapié en los mensajes que tienen sus letras». En este supuesto «compromiso social» se funda y se construye la oposición entre ambos grupos. En la representación de que unos tienen mayor conciencia social y que a los otros «no les importa nada... y por eso escuchan cumbia, porque no les da para más». Este «no les da para más» es enunciado frecuentemente con un apelativo racista, que paradójicamente, no tiene en cuenta el color de piel: «son negros cabeza», se dice de los/as «cumbieros/as». Y cito palabras de una vecina del barrio:

Pero no negros de piel, son negros de alma, de acá...

(esta última palabra la dijo mientras se señalaba la sien, haciendo clara alusión a la «supuesta» falta de inteligencia).

¿Qué hace que «roqueros» y «cumbieros», aún compartiendo muchas de sus experiencias de vida, las procesen y expresen culturalmente de maneras tan disímiles, e incluso, opuestas? «Parte de la razón por la 
cual la gente que, aún compartiendo los valores centrales que una particular expresión musical representa o 'actúa', no construye su identidad alrededor de dicha expresión musical, es porque los seres humanos somos en realidad una compleja combinación de múltiples sujetos conviviendo en un solo cuerpo, sujetos que son precariamente suturados en una imaginaria identidad unitaria a través de la construcción narrativa de tal unidad ficcional» (Vila, 2000). La propuesta analítica viene a plantear que las pertenencias e identificaciones con un grupo u otro dependen de cómo los sujetos han construido su identidad. Es decir, la forma en la cual han procesado sus experiencias y cómo las mismas han terminado cristalizándose en diversas elecciones musicales, las cuales pueden ser opuestas o complementarias dependiendo de los múltiples factores señalados.

Teniendo en cuenta todo lo anterior, tematizar la cuestión de identidades de clase no parece una tarea sencilla, máxime cuando el abordaje trabajado me (y nos) enfrenta a los debates en torno a la pertenencia social o de clase de los sujetos, y la expresión de la misma en términos culturales (Thompson, 1980 y 1990). Como este debate también excedería los límites de esta discusión, es pertinente señalar algunas cuestiones sobre la música popular y los sujetos pertenecientes al amplio mundo de las clases populares urbanas que tienen a la cumbia, «el más popular de los géneros populares» como su elección (casi) exclusiva. ${ }^{3}$ Dice Alabarces et al. (2007): «sólo es posible reponer un significado fuerte de lo popular leyéndolo como la dimensión de lo subalterno en la economía simbólica. Entonces, nuestro análisis de la música popular debe pensarse en ese contexto: en el de una distribución compleja y estratificada de los bienes culturales, donde lo popular ocupa posiciones subalternas». Así, hablar de mujeres y varones jóvenes y pobres que organizan su identidad en torno al consumo de la cumbia — esto es, «ser cumbieras y cumbieros»— está señalando una segmentación, y en el mismo movimiento, una deslegitimación: la de ese consumo cultural, y por extensión, la de sus públicos.

¿Dónde podemos ver expresadas esas deslegitimaciones? Fundamentalmente en las representaciones y discursos públicos, lo que conforman lo que Feixa (1998) denominó «imágenes culturales». Las

3 A excepción de algunos artistas melódicos latinos como Marco Antonio Solís o Ricardo Arjona (elegidos preferentemente por las mujeres), no se cuentan entre las elecciones musicales de estos jóvenes otros estilos musicales de manera significativa. 
imágenes culturales construidas en la actualidad sobre estos/as jóvenes pertenecientes a las clases populares urbanas - que viven, trabajan, estudian y consumen en condiciones de desigualdad distributiva, tanto de bienes materiales como simbólicos-, están relacionadas con sujetos con una escasa posesión de capital y competencias culturales legítimas y legitimadas (Bourdieu, 2007), que establecen relaciones inestables y precarias con el mercado laboral, y que algunas veces pueden atravesar la delgada y confusa línea entre actividades legales e ilegales debido, sobre todo, a una especie de «código moral propio» (distante de los valores morales legitimados en nuestra sociedad). Dicen Isla y Míguez (2003) «la noción de 'violencia delictiva incluye sólo a los hechos 'ilegales', o sea, hechos que infringen las leyes constitutivas del Estado y la sociedad, pero que al mismo tiempo han sido 'reconocidos', son 'visibles' y 'denunciados'. El problema radica en que encontramos en nuestros trabajos de campo un abanico de prácticas que son ilegales y violentas desde la perspectiva del sistema jurídico vigente, pero no desde la perspectiva de los actores». ${ }^{4}$

Esa deslegitimación de sus prácticas, sus saberes y sus elecciones estéticas, ¿habilita a ciertos sectores de la sociedad a emitir juicios de valor homogeneizadores y condenatorios sobre este grupo social juvenil? ¿Es posible pensar que el rechazo que los cumbieros y cumbieras sienten y enuncian hacia «los chetos» esté fundado o al menos relacionado por la forma en como ellos/as experimentan esa deslegitimación, traducida a veces en discriminación? Muchas de las expresiones que las «cumbieros/as» utilizan para referirse a los «chetos», terminan generando un mecanismo donde ellos eligen discriminar (insultando, desvalorizando, etcétera) a aquellos que los discriminan. Lo que llama la atención es que esa puesta en escena y el discurso de actitudes discriminatorias vuelve a dar en un contexto de organización social jerárquica, en la cual muchos de esos «chetos» son más aceptados (y por lo tanto legitimados) que los/as «cumbieros».

$\mathrm{Y}$ ¿qué pasa con los «roqueros», con quienes pueden compartir experiencias de vida, pero no la forma de procesarlas en términos culturales? La brecha que se abre en función de los valores y principios que estarían defendiendo los roqueros, hace que la distancia sea muchas

4 Debatir sobre la definición nativa de actividades ilegales e ilegítimas para contrastarla con la «moral y los valores socialmente legitimados» requeriría de una discusión complementaria a la propuesta. Por ese motivo, sólo hemos decidido citar la problemática pero no profundizarla. 
veces insalvable y otras tantas, puedan dejarse de lado, permitiéndoles compartir el tiempo libre y, por qué no, la cumbia y la bailanta. Varios de los integrantes del grupo, de hecho, combinaban su condición «roquera» (banda de rock, ensayos, recitales propios y de bandas amigas o ya consagradas) con noches de «bailanta» sin que ello les signifique una contradicción o que se enfrenten a una traición de uno a otro grupo. Esto permite dar cuenta de que las oposiciones, según el contexto, pueden a veces construirse como arbitrarias o negociadas. «Las alianzas que permite la música son en realidad alianzas entre alguna de nuestras múltiples identidades en particular y aquellas partes de la identidad de los otros que coinciden estratégicamente en tal o cual actuación o audición musical (...) Los individuos están continuamente estableciendo distintas alianzas a nivel de sus diferentes identidades a través de los valores representados o actuados por diversas prácticas musicales» (Vila, 2000). Así, ser «roquero» durante la mayor parte del tiempo y concurrir a una bailanta con el grupo de amigos durante el fin de semana, no plantea para los jóvenes de este grupo problema alguno.

Por otra parte, y pensando en las «imágenes culturales» de Feixa, podríamos preguntarnos: ¿cómo experimentan estas mujeres y varones jóvenes las representaciones que de ellos circulan, por ejemplo, en los medios de comunicación masiva, respecto de su supuesta «ignorancia» o «ausencia de competencias culturales». Y, ¿qué opinan y cómo los afecta la relación directa que se establece entre varón joven, pobre y bailantero igual a un sujeto peligroso; mujer joven, pobre y bailantera igual a «bardera» y «atorranta»? Entonces, tenemos dos oposiciones bien diferenciadas, que, expresadas en el plano de los consumos culturales, ponen al descubierto, insistentemente, nuevos interrogantes: ¿son estas oposiciones tan categóricas? ¿son permanentes o difusas? ¿la oposición es sólo discursiva o tiene algún correlato material? Y si es así, ¿de qué tipo?

Todas estas preguntas representan aún cuestionamientos que no pueden ser respondidos en todo su alcance. En principio son invitaciones a la reflexión, a la incomodidad e incluso, al (auto) cuestionamiento.

\section{EL GÉNERO (O LA FORMA DE REPRODUCIR LAS DESIGUALDADES AL INTERIOR DEL PROPIO GRUPO)}

Una cita de Laclau (1990) permite retomar los dos puntos tratados anteriormente (la condición etaria y de clase social) y poder conjugar- 
los con el punto a desarrollar (la cuestión de género): «Si... una objetividad logra afirmarse parcialmente, sólo lo hace reprimiendo lo que la amenaza. Derrida demostró que la constitución de una identidad siempre se basa en la exclusión de algo y el establecimiento de una jerarquía violenta entre los dos polos resultantes: hombre/mujer, etcétera. Lo peculiar del segundo término queda así reducido a la función de un accidente, en oposición al carácter esencial del primero. Sucede lo mismo con la relación blanco-negro, en que el blanco, desde luego, es equivalente a 'ser humano'. «Mujer» y «negro» son entonces «marcas» (esto es, términos marcados) en contraste con los términos no marcados de «hombre» y «blanco». El traductor aclara que «marcados» debe entenderse aquí no sólo como «señalados», sino también con el matiz de «sospechosos» o «condenados».

Las mujeres y varones jóvenes y pobres cumplen con esta condición de sujetos marcados como resultado de la conformación y aplicación de esa «jerarquía violenta». Pero, ¿qué sucede al interior del propio grupo con esas (¿otras?) jerarquías? ¿Se mantienen? ¿Se refuerzan? ¿Adquieren otros sentidos?

Previamente, es necesario aclarar qué significa abordar las relaciones entre los miembros del grupo desde una perspectiva de género. El concepto de género se define como «una forma de denotar las 'construcciones culturales' sobre los roles apropiados para mujeres y hombres» (Joan Scott, 2000). Es decir, al hablar de género nos referiremos tanto a las prácticas de mujeres como de varones, haciendo hincapié en las representaciones que el mundo social en el que viven ha construido y definido como esperables o deseables para cada uno, y cómo los propios actores aceptan, resisten o negocian con las mismas.

La categoría de subalternidad incluye, como ya se planteó, a las mujeres entre uno de los grupos históricamente oprimidos. Conjuntamente con la pregunta ¿puede hablar el sujeto subalterno?, Spivak (1977) señala la cuestión de la «mujer» como especialmente problemática. «En una palabra: si se es pobre, negra y mujer la subalternidad aparece por triplicado». Así, nos encontramos con que las mujeres objeto de este trabajo estarían «marcadas» y «condenadas» por ser, además de mujeres, jóvenes y pobres. De la condición de pobreza puede desprenderse, como ya dijimos, el apelativo racista. ${ }^{5}$

5 Es decir, en la Argentina, la categoría de «negro» no funciona en estricta relación con el color de piel, sino con una forma discriminatoria que conjuga, de manera casi análoga y perversa, esa condición de pobreza 
La desigualdad distributiva de bienes materiales, simbólicos y eróticos (Fernández, 2006) pone siempre a las mujeres en desventaja, aun en relación con sujetos de su misma pertenencia social; no hay en este caso una preponderancia de la clase sobre el género (o viceversa) sino una conjunción compleja, y a veces contradictoria, entre ambos. A las preguntas: ¿Se identifican primero como jóvenes o como pobres? ¿O primero como mujeres y varones jóvenes, y luego como pobres? Solo podemos responder «depende del contexto, de determinadas situaciones, del estado de relaciones (jerárquicas o simétricas) dentro del grupo, con otros grupos de jóvenes y con el mundo adulto». Dependiendo del momento y de las relaciones de fuerza, puede que prefieran o les convenga posicionarse, ser o mostrarse como jóvenes, pobres, varones o mujeres, o una conjunción de algunas de ellas. Sin embargo, esto no quiere decir que la identidad se construya sólo de manera estratégica y no perdure más allá de un contexto determinado, lo que sí se puede afirmar es que no son fijas ni estáticas. «Las identidades nunca se unifican y en los tiempos de la modernidad tardía, están cada vez más fragmentadas y fracturadas; nunca son singulares, sino construidas de múltiples maneras a través de discursos, prácticas y posiciones diferentes, a menudo cruzados y antagónicos» (Hall, 1996).

¿Qué ocurre con la construcción de masculinidades y femineidades en este grupo? El trabajo de campo desarrollado durante casi un año en el barrio y la bailanta — dos espacios de socialización fundamentales en las vidas cotidianas de estos jóvenes- permitió observar que las identidades de género se construían de acuerdo a un parámetro de heterosexualidad muy marcado, donde la homosexualidad era fuertemente sancionada. En el caso de los varones la alusión a una supuesta condición homosexual de otro varón era considerada uno de los insultos más graves. La masculinidad hegemónica en los sectores populares urbanos se caracteriza por «la posesión de las cualidades masculinas: los «huevos», la fuerza física, la valentía, etcétera. El nohombre se caracteriza por la carencia de estas cualidades. A través de

estructural a una cuestión biológica: la raza. Nuevamente aparecen «las imágenes culturales»: se produce una metonimia entre «negro» y los pobres, ignorantes y «vagos» como si fueran uno solo. Y aquí también pesa la cuestión de la herencia: muchas afirmaciones de sentido común giran en torno al carácter hereditario de esas condiciones sociales, como si las mismas fueran producto de la «genética» y no de una organización social estratificada, desigual y profundamente injusta. 
la construcción de una alteridad homosexual, se distingue del sexo opuesto y de aquellos grupos o sujetos que, según sus propios parámetros sociales, no encajan en su modelo ideal» (Garriga 2005). ${ }^{6}$ Los varones se distinguen así no sólo de la «natural debilidad femenina» sino de todas aquellas personas que no cumplan con su concepción de lo que un hombre «debe ser».

En cuanto a las femineidades, Fernández (2006) dice «al mismo tiempo que es necesario incluir la opresión de género dentro de otras formas de opresión, esto no puede obviar la elucidación de las formas específicas que la opresión adquiere cuando de géneros sexuales se trata. En tal sentido, habrá que distinguir la particularidad de las estrategias de subordinación cuando el colectivo que debe mantenerse en la desigualdad distributiva son mujeres. Y dentro de este grupo, cómo son los dispositivos puestos en juego en determinado momento histórico, clase social, grupo etario, etcétera» (cursivas de la autora) (Fernández, 2006). Esto es, la construcción de las femineidades no se da como un proceso en el cual las mujeres construyen sus «formas de ser» para distinguirse «lisa y llanamente» de las de los hombres. Ese proceso de construcción se da en condiciones de desigualdad, donde la diferencia - una vez más pero en este caso al interior del grupo con el que se comparte la condición etaria y de clase- es siempre jerárquica: al haber alguien que se considera (porque ha sido construido como) superior, necesariamente se instituye al otro como inferior.

a) Masculinidades: dinero, violencia y aguante

El aspecto que no puede quedar fuera en relación con la masculinidad es el trabajo, por el peso que ello tiene en su imagen de «actual o futuro proveedor», ya sea de las mujeres (madre, esposa, novias, hermanas) o niños a su cargo; o eventualmente del hogar, sosteniendo o colaborando con la economía doméstica. A los varones del grupo, por ejemplo, los preocupaba o condicionaba no tener dinero para salir o comprar ropa. El ideal de varón aparecía fuertemente ligado, en este caso, a la idea de «demostrar que podían».

6 Si bien Garriga elabora esta conclusión como resultado de su trabajo de campo con hinchadas de fútbol, las conclusiones nos parecen más que pertinentes a la hora de describir lo que observamos en nuestra propia experiencia etnográfica. 
Pero las condiciones objetivas en las que se insertaban en el mundo laboral, muchas veces distaban mucho de la situación ideal o soñada del "proveedor que todo lo puede». La mayoría de los varones del grupo había abandonado la educación formal, antes de terminar la primaria o apenas comenzado la secundaria, insertándose en el mercado de trabajo de manera temprana y precaria. Algunos continuaban estudiando y buscaban trabajo o «changas» a contra-turno de la escuela. Sus motivos están relacionados, además de los antes mencionados, con el deseo de tener recursos para sus gastos personales y evitar sermones de los padres que no quieren que sus hijos estén todo el día sin hacer nada. Nacho (17 años), por ejemplo, tuvo su primer empleo como ayudante en una panadería. Trabajaba de noche y su situación laboral no estaba regularizada ya que en ese entonces tenía catorce años. Germán (16 años), su hermano, siguió estudiando un tiempo más, pero faltaba a la escuela cada vez que le salía una «changuita» para cortar el pasto en alguna casa quinta de los alrededores, o ser asistente de pintor en obras en construcción de la Capital. Hacia fines del 2006 había quedado libre en la escuela por las faltas y a comienzos del 2007 no había retomado los estudios. Esta situación de precariedad laboral hacía que las posibilidades de sostener en la práctica un discurso de proveedor fuera, a veces, poco factible. Entonces el «poder» debía pasar a demostrarse en otros ámbitos.

Esa otra demostración está la ligada a la valentía, donde el uso de la fuerza física y la destreza del cuerpo son los principales protagonistas. Muchas de esas prácticas son en oportunidades definidas como violentas. «Las interpretaciones que conciben a la violencia como una acción irracional propia de un estado de incivilización evitan ahondar en las representaciones sociales de estas acciones y, por esta razón, no aprehenden los vínculos con otras prácticas [...] La violencia debe ser interpretada como una construcción cultural que tiene distintas fisonomías según las prácticas y representaciones que la nutren de significación, una acción con igual sentido que otras acciones sociales» (Garriga, 2005). Para este grupo de varones jóvenes la «violencia», tanto física como verbal, representaba una forma de relación entre ellos y con otros sujetos o grupos. En cuanto a la violencia verbal, los insultos más comunes eran: «puto», «gato», «mulo» «cagón» o «garca», «rata» $\mathrm{y}$ «tumba» 0 «tumbero». ${ }^{7}$ La mayoría de ellos pueden significar

7 Varias de estas expresiones requieren aclaraciones. «Puto» alude a la condición homosexual de otro varón. «Gato» tiene múltiples acepciones, una de ellas puede ser «boludo», «tonto». «Mulo» es aquel que 
cosas distintas según el contexto. No es lo mismo decirse «gato» entre ellos de manera amistosa o en broma, por ejemplo, «che, gato, vamos a comprar»; que alguien que no es del grupo nombre a alguno de ellos despectivamente como «gato».

En cuanto a la violencia física, las prácticas más comúnmente observadas fueron, para los varones, las peleas en las bailantas. Las mismas podían comenzar por un empujón de otro/s (adrede o sin querer), por una disputa anterior (del barrio, la escuela, el ámbito laboral, etcétera) o por una mujer: ya sea porque alguno se había «zarpado» con la novia de otro (mirándola o tocándola) o porque dos o más varones estaban disputándose la atención/el amor de alguna chica. Las peleas tenían dos instancias: una primera en dónde los jóvenes comenzaban a empujarse y darse golpes de puño y patadas, y la segunda en la cual entraban en acción los guardias de seguridad, más conocidos como «patovicas». Éstos, muchas veces, no cumplían necesariamente con la función de disuadir la pelea sino que ingresaban a la misma como un contendiente más. Dos características se pueden adjudicar a las peleas: virulencia y frecuencia. Prácticamente todas las noches que compartí con el grupo hubo una o varias peleas en las cuales participaron la mayoría de los miembros masculinos del grupo (los que no lo hicieron, fueron fuertemente criticados) y tuvieron una duración considerable. ¿Cuál era el sentido de estas acciones para estos jóvenes? ¿Por qué las peleas son parte de la dinámica habitual de la bailanta? La respuesta parece estar nuevamente en los valores característicos de la masculinidad en sectores populares. Ellos tienen que mostrar constantemente que tienen aguante, que «van al frente» cada vez que una situación lo amerita, y nunca pasar por cobardes o «flojitos»; el que «se come los mocos» y «arruga» falta a los códigos de la moral masculina (Archetti, 1999) y por ende es sancionado o segregado del grupo.

\section{b) Femineidades: entre lo tradicional y las nuevas formas de ser mujer}

Respecto a las mujeres, la responsabilidad en las tareas domésticas y el cuidado de hermanos menores es un tema ineludible y de mucho peso al

hace cosas para otro que tiene más poder que él. Tanto «gato» como «mulo» tienen origen en el lenguaje carcelario. «Cagón» o «garca» es aquel en quien no se puede confiar porque te traiciona. «Rata» es el tacaño. Y ser «tumba» o «tumbero» significa haber estado preso. 
analizar las configuraciones actuales de los roles de género en este grupo. «Se puede sostener una división básica que corresponde a la división sexual del trabajo más primitivo: las mujeres paren a los hijos, y por lo tanto, los cuidan: ergo, lo femenino es lo maternal, lo doméstico, contrapuesto con lo masculino como lo público» (Lamas, 2000).

Algunas de las mujeres del grupo continúan la educación secundaria y, al igual que los varones, lo combinan con trabajos a contraturno. Karina (14 años) hermana de Nacho y de Germán, va a la escuela en el turno de tarde. Por la mañana se encarga junto a su madre de las tareas domésticas (lavar, planchar, cocinar, limpiar, hacer las compras, etcétera) y del cuidado de sus siete hermanos menores (bañarlos, darles de comer, enviarlos a la escuela, controlar las tareas escolares, etcétera). Cuando consigue algún trabajo temporario para realizar durante la mañana, sus hermanas menores, de 12 y 11 años, la reemplazan en los quehaceres domésticos. El dinero que gana cuidando chicos o ayudando en algún negocio lo utiliza para gastos personales (para comprar ropa o zapatillas, tarjetas para su celular o productos de perfumería y aseo personal), siempre y cuando la situación económica de la familia así lo permita; de no ser así, debe dárselo a su madre para cubrir gastos del hogar. Si bien los varones también deben prestar colaboración en algunas labores, como hacer compras, encargarse de las reparaciones del hogar, etcétera), la obligación que pesa sobre las mujeres da cuenta de la naturalización existente en relación con una división de tareas predeterminada según el género.

«La dicotomía masculino-femenina, con sus variantes culturales, establece estereotipos, las más de las veces rígidos, que condicionan los papeles y limitan las potencialidades humanas de las personas al estimular o reprimir los comportamientos en función de su adecuación al género» (Lamas, 2000). En las entrevistas con Karina y el resto de las chicas del grupo aparecían dos sensaciones: por un lado bronca o enojo por saber que sobre ellas pesaban esas responsabilidades, y por el otro resignación, porque sabían que las posibilidades de modificación eran mínimas. Ellas se encargaban de las mismas cosas (en mayor o menor medida) que en otro momento habían sido responsabilidad de su madre y su abuela, y que iban a serlo de sus hermanas chiquitas y, quizá, de sus propias hijas mujeres.

Como en muchas otras familias del barrio, la familia de Karina, Germán y Nacho lucha cada día contra numerosas injusticias y desigualdades, donde las sociales son sin duda las más obvias y omnipresentes; las de género muchas veces parecen estar ocultas o naturaliza- 
das, aunque no por eso son menos importantes, ni tampoco menos dolorosas.

Sin embargo, no todo en la vida de estas chicas era la cotidianidad del trabajo doméstico o la rutina de la escuela o el trabajo. También se podía observar un esfuerzo por constituirse como un tipo de mujer particular, en relación con las otras mujeres y, en especial, con los varones, relación en la que la palabra y el gesto de ese «otro» no les era indiferente. Así, se podían observar dos modelos (o tipos ideales) de mujeres: las «rescatadas» y «las barderas». Entre ambas se daba un juego de tensiones y críticas permanentes, donde lo que operaba claramente era el debate entre cumplir con el mandato de género y reproducir el rol tradicional de la joven mujer que desea convertirse en ama de casa, tener hijos, fundar un hogar, ocuparse de su marido, etcétera (Fernández, 2006) o desafiarlo y tener un rol más activo y trasgresor en su relación con los varones y con el resto de su entorno social. Estos modelos, al funcionar como tipos ideales, no eran cumplidos al pie de la letra ni clasifican a las jóvenes en uno u otro de manera permanente.

El espacio de las bailantas era un lugar particularmente interesante para observar la puesta en escena de estos modelos. ¿Qué hacían las mujeres cuando llegaban? Mientras los varones se preocupaban por mantener el espacio sin invasiones de otros grupos o por ir a la barra a comprar bebidas, las chicas bailaban, con alguno de los del grupo o entre ellas; esa era la actividad que desarrollaban durante la mayor parte de la noche.

Los chicos se encargaban no sólo de proteger el espacio propio sino a las mujeres del grupo, a quienes, por momentos, parecían considerar como su propiedad. Si alguien ajeno al grupo se acercaba y las invitaba a bailar, lo más probable era que Nacho, Tula o Rocky «se le fueran al humo»" ${ }^{9}$ y lo quisieran echar o pegarle por la osadía de su actitud. Este tipo de situaciones se repetía a menudo y varias veces en una misma noche. En una de ellas, le pregunté a Nacho cuál era el motivo por el que no querían que bailaran con un desconocido si, en definitiva, podía decirse que estaban ahí para eso. Él me contestó:

Si yo las dejo bailar con cualquier gil que viene y las saca, y después el flaco se zarpa, yo no puedo decir nada, porque ya las dejé... ¿cómo sé yo que el flaco no se va a zarpar si no lo conozco?

8 Otros integrantes del grupo.

9 Expresión que significa tirarse encima de alguien con intenciones de golpearlo o amedrentarlo. 
Esto da pauta para pensar de que ellos consideraban a las mujeres como parte de aquello que debían cuidar, como si fuera una obligación más dentro de todas las que tenían como los protectores del grupo.

¿Qué decían las mujeres de estas actitudes? Principalmente, se beneficiaban de ella. Aprovechaban tener a un grupo de varones corpulentos a su disposición para «zafar» de i) los que venían a invitarlas a bailar y no les gustaban físicamente, y ii) «los pesados» que efectivamente pretendían propasarse con ellas, intentando besarlas o tocarlas, o proponiéndoles que los acompañaran a «otro lugar», fuera de la vista y el control del grupo. Así, la idea de que los varones consideraban a las mujeres del grupo como propiedad suya, era — si se desea admitirmuy apropiada para las chicas en términos de beneficio. Ellas utilizaban esa protección cuando les era favorable, y cuando no, desarrollaban diversas maniobras para escabullirse de los controles de hermanos mayores, novios o amigos, y, como dicen ellas, «hacer la suya».

La más común de sus formas era ir al baño o «dar una vuelta para ver qué onda». En una de esas ocasiones, Karina, camino al baño, debía atravesar una ronda de jóvenes que le impedían el paso. Yo iba detrás de ella. Uno de los chicos se puso frente a ella e intentó besarla y agarrarla de la cintura. Karina primero lo apartó con un leve empujón, pidiéndole que la dejara pasar. Cuando había hecho unos pasos el joven volvió a insistirle pero esta vez le tocó la cola. Ella se dio vuelta y le dio una cachetada sin dudarlo. La actitud de Karina me sorprendió, porque mi impresión era que tenía una personalidad introvertida, inferida a partir de la observación de sus prácticas cotidianas y de sus propios relatos sobre ella. Esto me hizo pensar que la única herramienta de defensa con la que las mujeres cuentan no es la protección masculina, sino que también pueden defenderse solas. Y lo hacen.

Lo que puede deducirse de las actitudes más desafiantes de estas mujeres es que la obediencia que mostraban tener en el espacio doméstico, no necesariamente se trasladaba al espacio festivo y muchas veces «liberador» de la bailanta. Sergio Pujol (1999) afirma que el baile social no es sólo una práctica lúdica en la que las personas «pueden dejarse llevar por la música, las bebidas, el bullicio o el roce con otros cuerpos... lo que se hace y con quienes se lo hace tiene algún sentido, remite a un contexto social y desnuda la manera en que una sociedad funciona, sus valores, sus expectativas, sus deseos y sus prejuicios» (Pujol, 1999). Podría pensarse que esas «nuevas formas de ser» observadas en la bailanta pueden estar hablándonos de las aspiraciones de estas mujeres respecto del tipo de relación que desean y espe- 
ran establecer con un hombre: una relación en la cual el cuerpo de la mujer y las decisiones que ésta tome sobre él (básicamente, quién quiere que lo toque y en qué momento) forme parte de una de las premisas de los vínculos con los varones que ellas desean defender. Y una de las tantas formas de hablar, de expresarse, pero sobre todo, de modificar ciertas estructuras históricamente opresivas contra ellas.

\section{CONCLUSIONES}

Frente a la pregunta ¿puede hablar el sujeto subalterno?, este trabajo ha pretendido responder que sí, que sólo hace falta agudizar el oído, es decir, revisar nuestras herramientas como intelectuales comprometidos con la realidad social, para aprender a escucharlos/as y comprobar, como ya se dijo, que en verdad no sólo hablan sino que tienen mucho para decir. Más allá de los esfuerzos de muchos sectores políticos por silenciar las voces de los grupos oprimidos, éstos siguen esforzándose por hacerse escuchar.

Stuart Hall (1992) afirma: «La vida cultural ha sido transformada, sobre todo en Occidente, por las voces de los marginados. Dentro de la cultura, la marginalidad, si bien permanece en la periferia de la amplia tendencia cultural, nunca ha sido un espacio tan productivo como lo es ahora. Y esto no representa simplemente una apertura por la cual aquellos que están afuera pueden ocupar los espacios dominantes. Es también el resultado de la política cultural de la diferencia, de las luchas sobre la diferencia, de la producción de nuevas identidades, de la aparición de nuevos sujetos en el escenario político y cultural. Esto es cierto no sólo con respecto a la raza, sino también a otras etnias marginales, así como también respecto del feminismo y la política sexual en los movimientos gay y lesbiano, como resultado de una nueva forma de política cultural».

Las experiencias de las mujeres y varones jóvenes que presentamos aquí pretenden constituirse en un ejemplo más de la necesidad de defender el respeto por la diversidad cultural, pero no en el sentido de un «multiculturalismo seductoramente integrador», que deje por fuera las relaciones de poder existentes, sino orientado a cuestionar los prejuicios existentes en la sociedad argentina contemporánea respecto de ciertos sectores sociales, sus prácticas y sus elecciones tanto éticas como estéticas.

Si sus voces y sus cuerpos son reprimidos en tanto sujetos que combinan de manera compleja, contradictoria y estratégica, subalter- 
nidades de edad, de clase y de género, los jóvenes deben y pueden reclamar, oponiéndose a las imposiciones de aquellos que cumplen con la condición del «sujeto normal» (adultos, de clases medias o altas y varones). Los jóvenes pueden desafiar el poder del mundo adulto, descreyendo de la autoridad de aquellos que supuestamente debierán guiarlos, cuidarlos y contenerlos. Los pobres pueden denunciar la deslegitimación a la que sus prácticas son permanentemente sometidas y juzgadas, demostrando así que tienen conciencia del lugar que ocupan en la jerarquía social y también de su deseo de transformarla. Las mujeres pueden mostrar la opresión y la desigualdad a la que muchas veces son sometidas, y además demostrar que pueden rebelarse a partir de pequeños actos, a las injusticias de siempre. Los que aquí actúan y luchan, entonces, son los mismos que hablan, descreen, denuncian, reclaman y ejercen su derecho a desear, pero también a tratar de construir, día a día, una sociedad más igualitaria.

«Un modelo recurrente emerge: 'lo alto' intenta rechazar y eliminar lo 'bajo' por razones de prestigio y de estatus, únicamente para descubrir que no sólo es de alguna forma es frecuentemente dependiente del otro opuesto... sino también que lo alto incluye simbólicamente lo bajo, como el componente erotizante fundamental de su propia fantasía. El resultado es una móvil y conflictiva fusión de poder, temor y deseo en la construcción de la subjetividad: una dependencia psicológica sobre precisamente aquellos otros que están siendo rigurosamente opuestos y excluidos en el nivel social. Por esta razón, lo que es socialmente periférico es tan frecuente y simbólicamente central» (Hall, 1992). Porque desde esa periferia puede surgir, por qué no, una nueva forma de pensar y desear la constitución de lo centralmente valioso, en lugar de lo hegemónicamente central.

Buenos Aires (ARGENTINA), AGOSTO 2011

RECIBIDO: AGOSTO 2011

ACEPTADO: OCTUBRE 2011 


\section{REFERENCIAS BIBLIOGRÁFICAS}

Alabarces, Pablo, Daniel SAlermo, Malvina Silba y Carolina SPATARO (2008): «Música popular y resistencia (cultural) en la Argentina: una discusión en torno de los significados del rock y la cumbia». En PABlo AlABARCES y M. G. RodRíGuez (organizadores): Resistencias, sumisiones, mediaciones. La cultura popular en la Argentina contemporánea. Buenos Aires: Paidós.

ArChetTi, EduARdo (2003): Masculinidades. Fútbol, tango y polo en la Argentina. Buenos Aires: Antropofagia.

Bourdieu, PIERre (2007): El sentido práctico. Buenos Aires: Siglo XXI Editores.

CHÁves, MARIANA (2005): «Los espacios urbanos de jóvenes en ciudad de La Plata». Tesis Doctoral. La Plata: FCNYM, NNLP-CONICET (inédita).

FeiXa, Carles (1998): De jóvenes, bandas y tribus. Antropología de la juventud. Barcelona: Ariel.

FERNÁNDEZ, ANA MARÍA (2006): La mujer de la ilusión: pactos y contratos entre hombres y mujeres. Buenos Aires: Paidós.

GARRIGA ZUCAL, JOSÉ (2005): «'Soy macho porque me la aguanto’. Etnografía de las prácticas violentas y la conformación de identidades de género masculino». En PABlO AlabArCes et al.: Hinchadas. Buenos Aires: Prometeo.

GARRIGA, JosÉ (2008): «Ni chetos ni negros: roqueros». TRANS, Revista Transcultural de Música $\mathrm{N}^{\circ} 12$.

GIRALDO, SANTIAGO: Nota Introductoria a Gayatri Spivak: «¿Puede hablar el subalterno?». Revista Colombiana de Antropología,Vol. 39. Bogotá.

GROSSBERG, LAWRENCE (2006): «Stuart Hall sobre raza y racismo: estudios culturales y la práctica del contextualismo». Revista de Humanidades Tabula Rasa N005. Bogotá: Universidad Colegio Mayor de Cundinamarca.

HALl, StUART (1996): «¿Quién necesita identidad? En STUART HALl y PAUl Du GAY: Cuestiones de identidad cultural. Madrid: Amorrortu.

HALL, STUART (1992): "What is black in popular culture?». En RAIFORD A. Guins and Zaragoza Cruz (editores): Popular Culture: A Reader. London: Sage Publications.

Hall, Stanley (1904): Adolescence. New York: Appleton.

Isla, Alejandro y DANiel Miguez (2003): Heridas urbanas: violencia delictiva y transformaciones sociales en los noventa. Buenos Aires: Editorial de las Ciencias.

LAClAU, ERNESTO (1990): New Reflections on the Revolutions of Our Time Londres: Verso (citado en Stuart Hall, 1996).

LAMAS, MARTA (2000): «Introducción». En MARTA LAMAS (compiladora): El género. La construcción cultural de la diferencia sexual. México: UNAM. 
MARGULIS, MARIO Y MARCELO URRESTI (1998): «La construcción social de la condición de juventud». En CUBIDES, LAVERDE y VALDERRAMA (editores): 'Viviendo a toda' Jóvenes, territorios culturales y nuevas sensibilidades. Bogotá: Siglo del Hombre. Departamento de Investigaciones, Universidad Central.

Monod, JeAn (1970): Los Barjots. Etnologías de bandas juveniles. Barcelona: Ariel (citado en Chaves, 2005).

Pujol, Sergio (1999): Historia del baile. De la milonga a la disco. Buenos Aires: Emecé Editores.

SCOTT, JOAN (2000): «El género: una categoría útil para el análisis histórico». En MARTA LAMAS (compiladora): El género. La construcción cultural de la diferencia sexual. México: UNAM.

SPIVAK, GAYATRI (1999): «¿Puede hablar el sujeto subalterno?» Orbis Tertius $N^{\circ}$ 6, Año 6. La Plata: Centro de Estudios de Teoría y Crítica Literaria e Instituto de Investigaciones en Humanidades y Ciencias Sociales (IDIHCS), Universidad Nacional de La Plata.

Vila, Pablo (2000): «Música e identidad. La capacidad interpeladora y narrativa de los sonidos, las letras y las actuaciones musicales». En Mabel Piccini, ANa Rosas Mantecón y GRaciela SchmilchuK (coordinadoras): Recepción artística y consumo cultural, México: Consejo Nacional para la Cultura y las Artes, Instituto Nacional de Bellas Artes, Centro Nacional de Investigación, Documentación e Información de Artes Plásticas, Ediciones Casa Juan Pablos. 